\section{ATMOSPHERIC PRESSURE CHANGES OF LONG DURATION.}

$\mathrm{T}$ previous numbers of this Journal (vol. Ixvii., p. 224, and vol. Ixx., p. I77) I described a barometric variation of short duration and worldwide in extent which behaved in a see-saw manner in an easterly and westerly direction between antipodal parts of the earth. The investigation, which included the examination of pressure changes at ninety-five stations scattered over the globe, indicated that there was a transference of air from west to east and from east to west alternately, a surge, in fact, raising and lowering the mean annual pressure values. Thus, when the pressure in any year in India the East Indies, and Australia behaved alike, while the South American region behaved in an inverse manner. The present inquiry was therefore limited to these areas. For the first three a considerable amount of data is available, but this is not the case for the last-mentioned region; to mitigate this deficiency, curves for several separate stations have had to be employed in order to determine over several years the variation in operation there.

The first step taken to prepare the data for this comparison was to eliminate so far as possible the variation of short duration. This was satisfactorily accomplished by grouping the years in sets of four and employing the mean values of each of these groups; thus the means for the years 1873 to 1876 ,

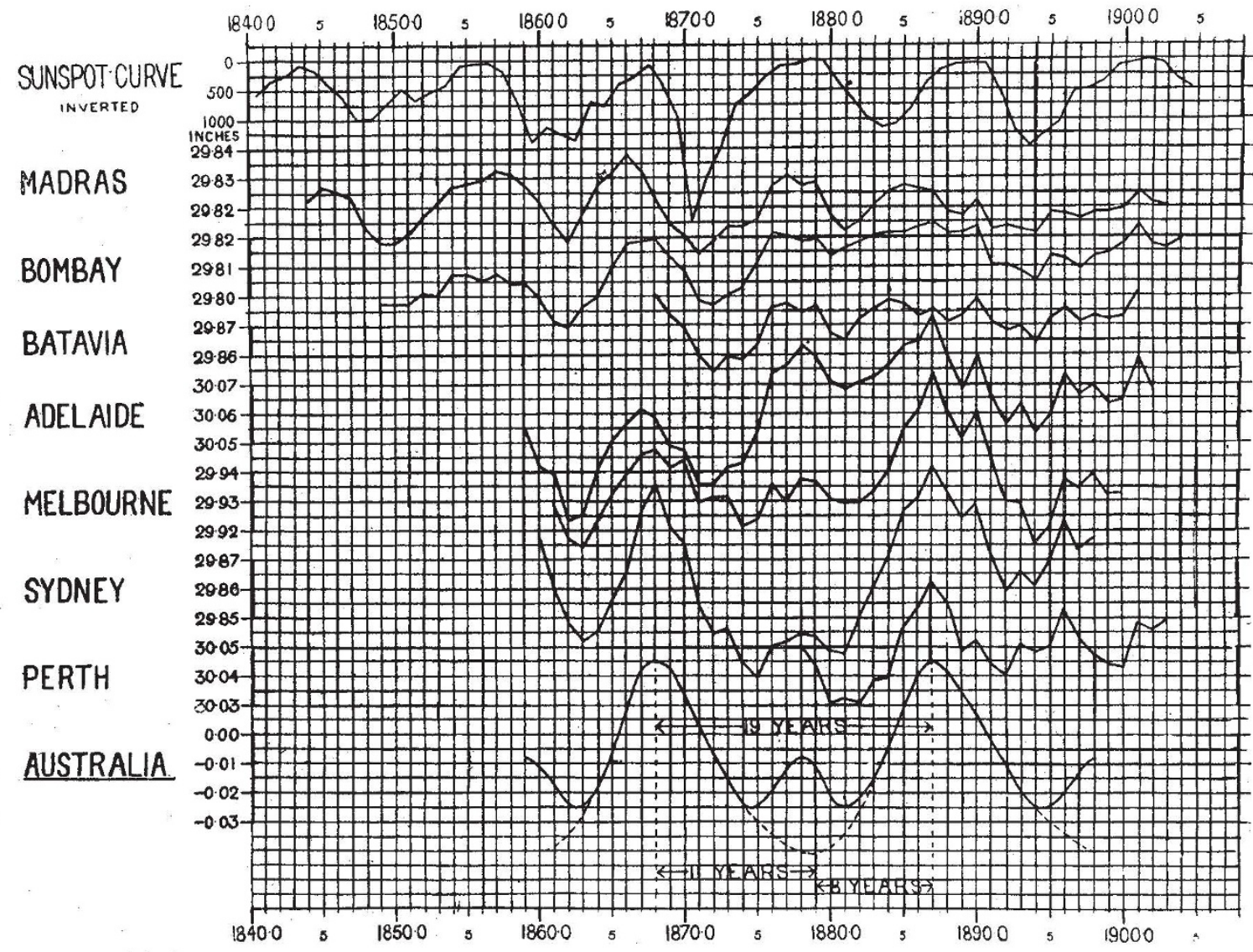

FIG. I.- - Long barometric changes which occur in the Indian, East Indian and Australian areas. The Indian variation is cornpared with the inverted sun-spot curve.

or Australia was in excess, that recorded in South America showed a deficiency.

During this inquiry it was noticed that there were changes going on which extended over a longer period of time than the short one (about 3.8 years) to which reference above has been made. In order to find out whether these long variations were similar all over the earth, or whether they also were of an opposite nature in different areas, several sets of long series of pressure observations have been carefully examined. The result of this limited survey recently formed the subject of a communication by the writer to the Royal Society, ${ }^{1}$ and the following is a brief account of the results arrived at in the paper.

In the case of the variation of short duration, India,

1 "Barometric Variations of Long Duration over Large Areas." By Dr. William J. S. Lockyer. Read June 21, 1906.
I 874 to 1877 , \&c., were determined. The curves here shown are all composed of such means, and are formed by connecting the points plotted on squared paper; the same scales are employed throughout.

Fig. I illustrates the series of curves, all drawn on the same scale, for the Indian, East Indies, and Australian areas. Bombay and Madras represent the pressure changes of the first, Batavia the second, and Adelaide, Melbourne, Sydney, and Perth are types for Australia.

An examination of these curves leads one to the following conclusions :-

First, the Indian curves are very alike, and suggest a variation of an oscillatory nature, the maxima or minima occurring about every ten or eleven years. Second, the amplitude of these curves, that is, the difference between the maximum and minimum

No. I919, voL. 74] 
values, has decreased considerably of recent years, and has nearly obliterated the eleven-year variation.

Going further afield, the curve for Batavia (East as before, and curves drawn for five stations. Three series of observations represent the Argentine Republic stations Cordoba, Goya, and San Juan, while

Indies) is very similar to that of Bombay. Coming Santiago (Chili) and Curityba (Brazil) are also used,

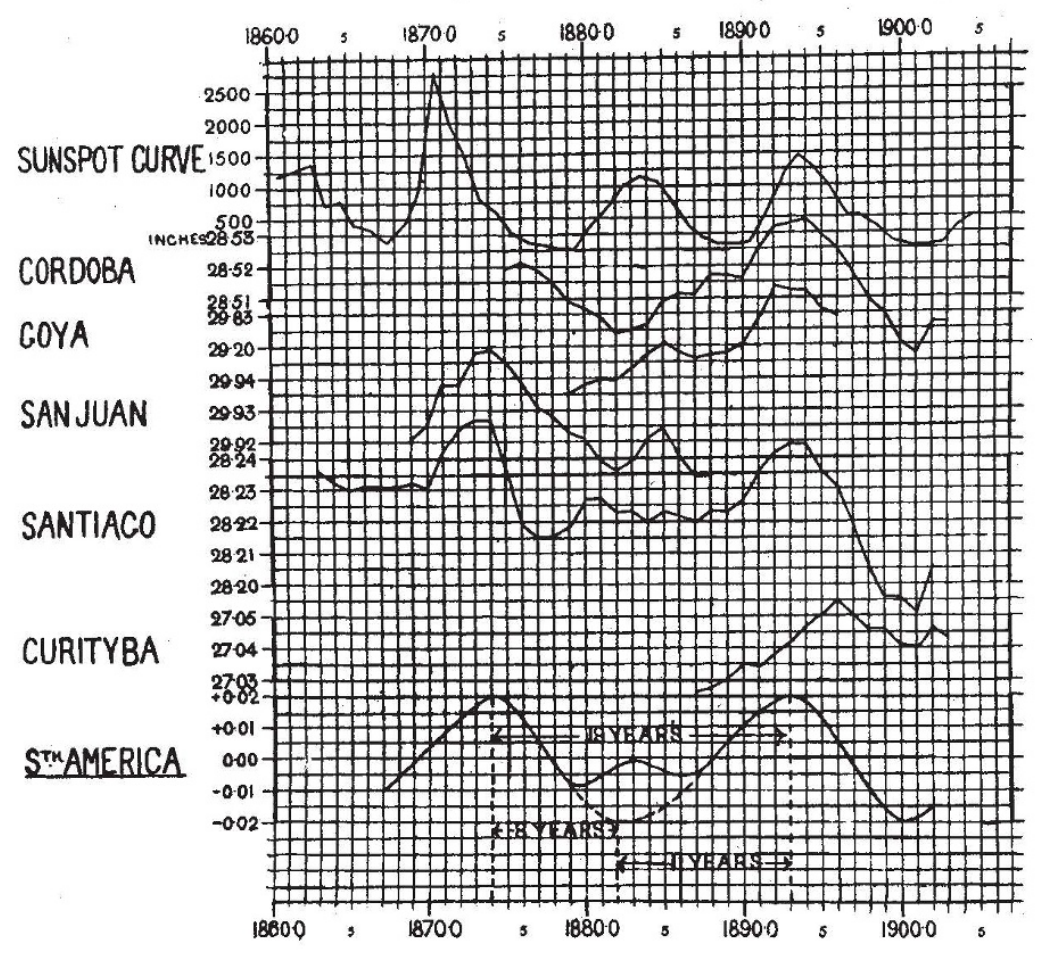

Fig. 2.--Long barometric variations in operation in South America. as they are stations situated more westerly and easterly respectively. Curves representing barometric changes at these places are all given in Fig. 2, and are drawn on the same scale. Although they extend over different periods of time, there is sufficient overlapping in all cases to allow one to draw conclusions as to the general kind of variation over this area.

As was done in the case of Fig. I, a curve is here drawn at the foot of the South American curves to show the general nature of the variation in this region. Two principal maxima are very obvious about the years 1874 and 1893 , while there seems to be an indication of a subsidiary maximum the mean of which is about the year 1883. We are here in the presence of a barometric change of long duration the principal maxima of which are also about nineteen years apart, so far as these observations inform us.

The question now arises, How does this South American variation compare with those shown to exist in India and Australia? This can be easily answered by comparing the curves brought together in Fig. 3.

The first point of importance is to the Australian continent, it will be noticed that that the South American and Australian curves have the eleven-year variation is well indicated in the principal maxima about nineteen years apart, while Adelaide curve, but the amplitudes are much greater. situated between them is another maximum of a subParticular attention is directed to the maximum about the years $1876-$ 1878 , because in the curves for Melbourne, Sydney, and Perth this becomes quite insignificant. In fact, it is the dropping out of this maximum which gives the Australian curves quite a different appearance from those of India, although in many other respects they closely resemble the indian changes.

The Australian curves thus indicate two principal maxima about the epochs 1868 and 1887 , with an intermediate subsidiary maximum about 1878 ; the principal maxima are thus nineteen years apart. The curve given at the bottom of Fig. I is drawn to represent in a general manner this variation, and to serve as a comparison to the other curves which follow.

An examination of the South American pressures was next undertaken. Here, as I have said before, the data are not too numerous, but I think they are sufficient to demonstrate a long variation that is in operation and the epochs of the maxima and minima.

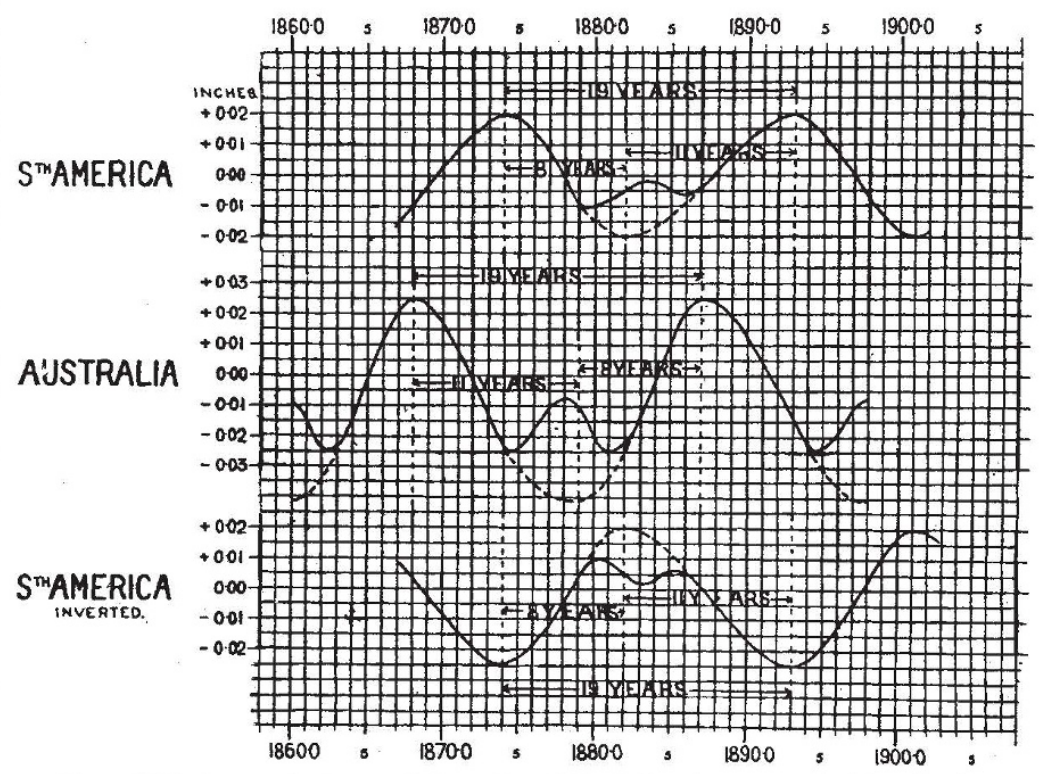

Fig. 3.-The barometric changes in Australia and South America compared with each other.

The same method of four-year means was employed No. I9I9, voL. 74]

sidiary nature. The second is that the epochs of these maxima in these two widely separated areas are not coincident. Further, we are not here in the 
presence of a barometric see-saw, or opposite pressure variation, because the Australian maxima do not occur simultaneously with the South American minima; there seems to be a general time-difference of phase amounting to about six y.ears, the epochs of the Australian maxima preceding those of the South American region. If a see-saw did exist, then the inverted South American curve should represent the Australian variation. That this is not so will be seen by comparing the two lower curves in Fig. 3 .

It will thus be seen that the South American pressure type is closely similar to that existent in Australia, but unlike that in operation in India.

The magnitudes of these changes of pressure from year to year are by no means insignificant. The following table shows in compact form approximate measures of the amplitudes of the curves in the cases of both the short and long variations. The third and fifth columns of figures represent, in percentages of the annual variations, the amplitudes given in the second and fourth columns of figures:-

\section{Pressure Amplitudes.}

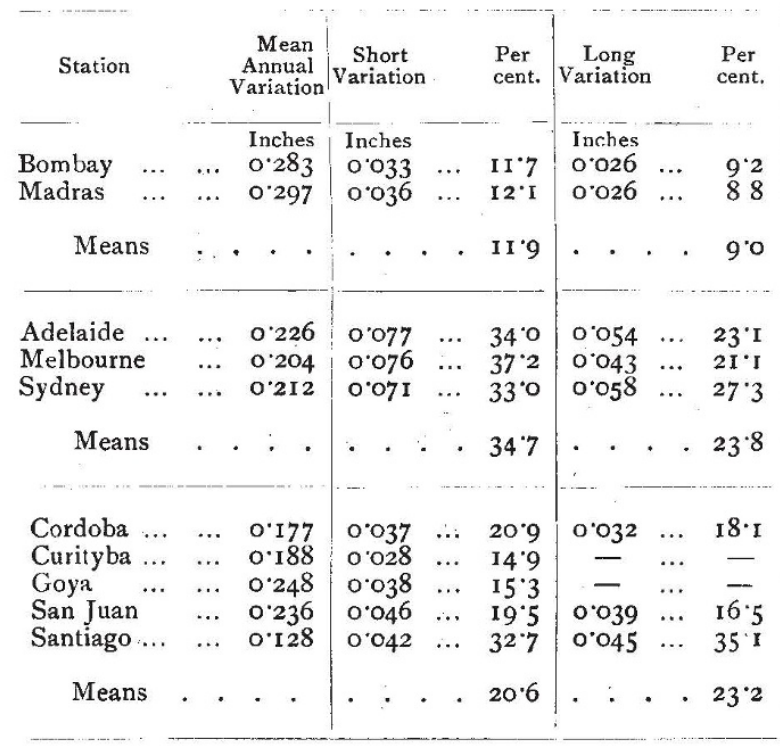

\begin{tabular}{|c|c|c|c|c|}
\hline \multicolumn{5}{|c|}{ Summary. } \\
\hline & & $\begin{array}{l}\text { Per cent. } \\
\text { I I } 9\end{array}$ & & $\begin{array}{c}\text { Per cent. } \\
g^{\circ} \circ\end{array}$ \\
\hline rica ... & $\begin{array}{l}\cdots \\
\cdots\end{array}$ & $20 \cdot 6$ & $\ldots$ & $23 \cdot 2$ \\
\hline alia & $\ldots$ & 347 & $\ldots$ & 23.8 \\
\hline
\end{tabular}

The brief summary at the foot of the table indicates an approximate mean value of the percentages for each region. In the case of Australia, for example, the fact is made apparent that the amplitude of the variation of short duration amounts to as much as 35 per cent. of that of the mean annual variation, while the variation extending over nineteen years reaches nearly 25 per cent. Such large pressure changes must therefore play an important part in producing variations in the seasonal weather from year to year.

With regard to the origin of these long barometric changes, it is interesting to note that the Indian pressure curves resemble in general the inverted curve representing solar activity as deduced from the area of sun-spots. This fact has for many years been known, and was pointed out by Brown, Hill, Eliot, Blanford, Douglas Archibald, and others. It will be seen from the curves, however, that the re- semblance was far more striking before the year 1880 than after it.

Since the Australian curves are allied to but somewhat modified forms of the Indian variation, it seems possible that this modification may be due to some terrestrial cause.

Mr. H. C. Russell, who is a strong advocate of a nineteen-year cycle of weather in Australia, has been led to discard solar action and to consider the moon as being the prime mover or origin of this cycle, a suggestion which he put forward in 1870 , and again in 1896 .

The present discussion of the barometric pressures seems to indicate that the family likenesses between the Australian and Indian curves, here shown in Fig. I, and between the Indian curves and the inverted sun-spot curve, are sufficient to suggest for the Australian nineteen-year variation a solar origin with a terrestrial modification without having to appeal to lunar action.

William J. S. Lockyer.

\section{SIR WALTER LAWRY BULLER, K.C.M.G.} F.R.S.

SIR WALTER LAWRY BULLER, who died on July 19 at Pontdail Lodge, Hampshire, will be remembered long in the scientific world on account of his accurate and sumptuous works on the ornithology of New Zealand. He was a son of the Rev. James Buller, of Canterbury, in the Southern Island, and was born in $18{ }_{3} 8$. He was proud of being a New Zealander, and passionately devoted to all that concerned Maoriland. At the age of twenty-four, and for ten years subsequently, he filled the post of Resident Magistrate and Native Commissioner and Judge of the Native Land Court of New Zealand. Few had so intimate a knowledge of the Maoris as he possessed. In 1865 , during a critical period of the Maori War, when Sir George Grey, the Governor, determined to take a personal hand in the contest in his endeavour "to quicken the slow dragging on of the military operations," Sir Walter served as a volunteer on his staff, and had the honour of being mentioned in despatches.

From an early age Sir Walter was a close observer of the birds of his native country. Fired no doubt by the example of (among others) Mr. Potts, an enthusiastic student and recorder of the habits of the birds of Canterbury, he, it would seem, very early conceived the ambition of making himself the authority on the birds of New Zealand. He was only thirty-four years old when, during the years $1872-3$, the publication of his "History of the Birds of New Zealand," a quarto volume illustrated by coloured plates by Keulemans, placed him at once in the undisputed position of ornithologist par excellence of the colony. In bringing this splendid work to its successful birth he was greatly aided by the wide experience of his friend Dr. Bowdler Sharpe. The persistent exploration of the recesses of the country and his own continued study of its avifauna soon showed him that he had made but a contribution to the history he had undertaken. After fifteen years he brought out a second edition, in two costly folio volumes, also profusely illustrated by Keulemans, which attained a success which few bird books have ever met with. For seventeen years more Sir Walter continued gathering in the aftermath of his already great harvest, the results of which he had determined to issue as a supplement in two volumes, which, superbly illustrated like their predecessors, were only quite recently distributed.

No. I9I9, VOL. 74] 